in vivo $34: 3171-3180(2020)$

doi:10.21873/invivo.12152

\title{
Clinical Significance of Tumor and Immune Cell PD-L1 Expression in Gastric Adenocarcinoma
}

\author{
DONG HYUN KIM ${ }^{1 *}$, GO EUN BAE ${ }^{1 *}$, KWANG SUN SUH $^{1}$, DAVID RYUMAN ${ }^{1}$, \\ KYU SANG SONG ${ }^{2}$, JU SEOK KIM ${ }^{3}$, SANG-IL LEE ${ }^{4}$ and MIN-KYUNG YEO ${ }^{1}$ \\ ${ }^{1}$ Department of Pathology, Chungnam National University School of Medicine, Daejeon, Republic of Korea; \\ ${ }^{2}$ CNYLAB, Daejeon, Republic of Korea; \\ ${ }^{3}$ Department of Internal Medicine, Chungnam National University School of Medicine, Daejeon, Republic of Korea; \\ ${ }^{4}$ Department of Surgery, Chungnam National University College of Medicine, Daejeon, Republic of Korea
}

\begin{abstract}
Background/Aim: The prognostic relevance of programmed cell death ligand-1 (PD-L1) protein expression in gastric cancer $(G C)$ remains controversial. The aims of the present study were to determine the correlations between tumor cell (TC) and immune cell (IC) PD-L1 protein levels with prognosis, and to determine the correlation between $P D$ L1 expression and different molecular GC subtypes. Materials and Methods: TC and IC PD-L1 protein levels were measured in 286 GC patients. The patients were classified according to the Cancer Genome Atlas and Asian Cancer Research Group guidelines using immunohistochemistry and in situ hybridization. Results: TC and IC PD-L1 protein levels were positively correlated with patient survival. TC PD-L1 expression was negatively correlated with tumor grade.TC and IC PD-L1 expression was associated with improved prognosis in Epstein-Barr virus negative $\left(E B V^{-}\right)$, microsatellite instability (MSI) rather than microsatellite stability (MSS) subgroup GC patients. Conclusion: PD-L1 protein expression in TCs and ICs can be used as a prognostic indicator for GC patients, particularly in the $\mathrm{EBV}^{-}, \mathrm{MSI}$, and MSS subgroups.
\end{abstract}

Gastric cancer (GC) is the fifth most common cancer and the third leading cause of cancer-related death globally (1). The standard of care for advanced GC is surgical resection

This article is freely accessible online.

*These Authors contributed equally to this study.

Correspondence to: Min-Kyung Yeo, MD, Ph.D., Department of Pathology, Chungnam National University School of Medicine, 266 Munhwa-ro, Jung-gu, Daejeon 35015, Republic of Korea. Tel: +82 425808232, Fax: +82 422808199, e-mail: mkyeo83@gmail.com

Key Words: PD-L1, tumor cell, immune cell, gastric cancer, prognosis. combined with chemo- or radiotherapy (2). Recurrence and/or metastasis commonly occur even following successful gastrectomy, and the 5-year survival rate for GC patients with metastasis is approximately $20 \%$ (3). Recently, the concept of immunotherapy has emerged; immunotherapy treats patients by acting on their immune system and boosting the immune response to identify and destroy cancer cells (4). Still, a limited number of chemotherapeutic agents have been used for GC patients, and immunotherapy can be an alternative to classic chemotherapy (5).

Cancer cells produce programmed cell death ligand-1 (PD-L1) to bind T-cells, inhibiting their activation (6). Blocking PD-L1 or PD-1 binding is the primary target of immunotherapy, which prevents cancer cells from evading the immune system (7). Anti-PD-L1 therapy was first introduced as a cancer treatment, subsequently, many clinical trials have been conducted to assess the efficacy of PD-L1 and PD-1 inhibitors in the treatment of multiple types of solid tumors (8). Clinical trials have demonstrated the therapeutic efficacy of anti-PD-L1 monoclonal antibody in $\mathrm{GC}$, and this modality has been proposed as a treatment option (9). However, the treatment was only effective in a limited number of patients, particularly those with microsatellite instability (MSI) rather than microsatellite stability (MSS) $(10,11)$.

The Cancer Genome Atlas (TCGA) and Asian Cancer Research Group (ACRG) studies identified distinct molecular GC subtypes. GC is classified based on the integration of 1) microsatellite status, 2) Epstein-Barr Virus (EBV) infection, 3) epithelial-to-mesenchymal transition (EMT) status, and 4) tumor protein 53 (TP53) expression, which are known to affect clinical outcomes of GC $(12,13)$. These findings provided a new subgroup classification system for GC to aid in the prediction of GC prognosis and the development of biomarkers for targeted therapy. Determining the relationship between PD-L1 expression and these newly identified molecular subgroups can 
determine which subgroups are most likely to respond to immunotherapy.

However, the prognostic relevance of PD-L1 protein expression in GC remains controversial, and prior studies have shown PD-L1 to have a promotive or suppressive role in GC (14). In the present study, we investigated the correlations between tumor cell (TC) and immune cell (IC) PD-L1 protein expression, and clinical/pathological variables and survival time in GC patients and in different GC subtypes. Measuring IC and TC PD-L1 in GC patients can be used to evaluate the potential role of PD-L1 in GC, and to classify patients with PD-L1 expression and molecular GC subtypes to predict patient prognosis.

\section{Materials and Methods}

Patients and tissue samples. This study was performed using 286 cases of gastric adenocarcinoma who underwent surgical resection at Chungnam National University Hospital (Daejeon, Republic of Korea) from January 2010 to December 2012. Patient characteristics and survival times were collected from medical records, and follow-up periods lasted up to 71 months. Patients who received preoperative chemo- or radiotherapy were excluded. Cancer stage was determined according to the American Joint Committee on Cancer TNM criteria in the Cancer Staging System, Eighth Edition (15). Hematoxylin and eosin-stained slides were reviewed by two experienced pathologists (G.E.B. and M.K.Y.), and the most representative (tumor and immune cell rich) areas were selected. To generate a tissue microarray, tissue columns (3.0 $\mathrm{mm}$ ) were punched from original paraffin blocks and inserted into new recipient paraffin blocks. All specimens were provided by the Biobank of Chungnam National University Hospital, a member of the Korea Biobank Network. The study was approved by the Institutional Review Board of Chungnam National University Hospital (CNUHIRB No. 2020-01-073). The study was retrospective, and a waiver of consent was approved by the Institutional Review Board.

Immunohistochemical staining analysis. Tissue sections $(4 \mu \mathrm{m})$ were cut from the tissue microarray using a microtome and mounted onto coated slides, which were then transferred to Dako (Glostrup, Denmark) and Ventana (Tucson, AZ, USA) automated immunostainers. Staining was performed according to the manufacturer's protocol using anti-PD-L1 (Ready-to-Use (RTU), clone SP263; Ventana, Tucson, AZ, USA), MLH1 (RTU, clone M1; Ventana), MSH2 (RTU, clone G219-1129; Cell Marque, Rocklin, CA, USA), MSH6 (RTU, clone 44; Ventana), PMS2 (RTU, clone EPR3947; Cell Marque), E-cadherin (M3612, 1:300; Dako), and p53 (M7001, 1:300; Dako) antibodies. In situ hybridization with EBV-encoded RNA was performed using Leica Biosystems (Newcastle Ltd., Newcastle Upon Tyne, UK) equipment. Formalin-fixed, paraffin-embedded PD-L1-positive NCI-H226 cell line were used as positive control for anti-PD-L1 (clone SP263) and human placental and tonsil tissues as negative controls. A normal gastric mucosa (MLH1, MSH2, MSH6, PMS2, E-cadherin, and P53) and a lymph node (EBV infected and noninfected) served as controls, and a primary antibody was omitted from the negative control.
TC PD-L1 (SP263) staining was scored with a $1 \%$ expression cut-off level. TC PD-L1 expression $<1 \%$ was categorized as "negative" and $\geq 1 \%$ as "positive," with significant separation in survival curves between $1 \%, 5 \%, 10 \%, 20 \%$, and $50 \%$ cut-offs. IC PD-L1 expression $<5 \%$ was categorized as "negative" and $\geq 5 \%$ as "positive," with significant separation in survival curves between $1 \%, 5 \%, 10 \%, 20 \%$, and $50 \%$ cut-offs. Microsatellite stability was determined based on mismatched repair protein (MMR; MLH1, MSH2, MSH6, and PMS2) expression, and GCs were categorized into MSI and MSS subtypes (16). Based on MMR protein expression and EBV in situ hybridization results, GC was divided into $\mathrm{EBV}^{+}, \mathrm{MSI}$, and MSS subtypes (17). p53 immunohistochemical staining patterns were divided into TP53 mutant and TP53 wildtype subtypes (18). E-cadherin status was evaluated based on loss of expression. Markedly decreased E-cadherin staining intensity was considered to be indicative of the EMT subtype $(19,20)$. Based on MMR, E-cadherin, and p53 staining, GC was divided into MSI, MSS/EMT, MSS/TP53 mutant, and MSS/TP53 wild-type subtypes (21).

Statistical analyses. Associations between TC and IC PD-L1 protein levels and clinic-pathological parameters of GC were examined using Spearman rank correlation coefficients and Mann-Whitney $U$ tests. For univariate analyses, overall and disease-free survival curves were generated using the Kaplan-Meier method with logrank test. Multivariate survival analysis was performed using the Cox proportional hazard regression model. $p<0.05$ was considered statistically significant. All analyses were performed using SPSS 24.0 (SPSS Inc., Chicago, IL, USA).

\section{Results}

GC patient characteristics. IC and TC PD-L1 expression was measured in $286 \mathrm{GC}$ samples. Patient age ranged from 21 to 86 years, with a mean age of 60.8 years and male/female ratio was 1.9:1. GCs were present in the upper (fundus and upper body) ( $\mathrm{n}=57)$, mid (mid and lower body) $(\mathrm{n}=105)$, and lower (antrum and pylorus) $(\mathrm{n}=124)$ locations. GCs were divided into intestinal $(n=176)$, diffuse $(n=73)$, and mixed $(n=37)$ types. GCs were diagnosed as tubular adenocarcinoma $(\mathrm{n}=176)$, poorly cohesive carcinoma including signet ring cell carcinoma $(n=49)$, and other $(n=37)$ based on WHO guidelines, $4^{\text {th }}$ edition (22).

GCs were $\mathrm{EBV}^{+}$, as demonstrated by in situ hybridization, in $17(5.9 \%)$ patients. Sixty $(21 \%)$ GCs were classified as MSI, and 226 (79\%) were classified as MSS. One hundred and seven (37.4\%) GCs showed a TP53 mutant type and 179 (62.6\%) showed TP53 wild type. Ninety-seven (33.9\%) were classified as EMT (marked decreased of E-cadherin) and 189 (66.1\%) showed preserved E-cadherin expression. Finally, GCs were divided into MSI $(n=60)$, MSS/TP53 mutant $(\mathrm{n}=85)$, MSS/TP53 wild-type $(\mathrm{n}=75)$, and MSS/EMT $(\mathrm{n}=65)$ subtypes according to ACRG classification.

Correlations between gastric adenocarcinoma PD-L1 expression and clinicopathologic variables. PD-L1 expression 

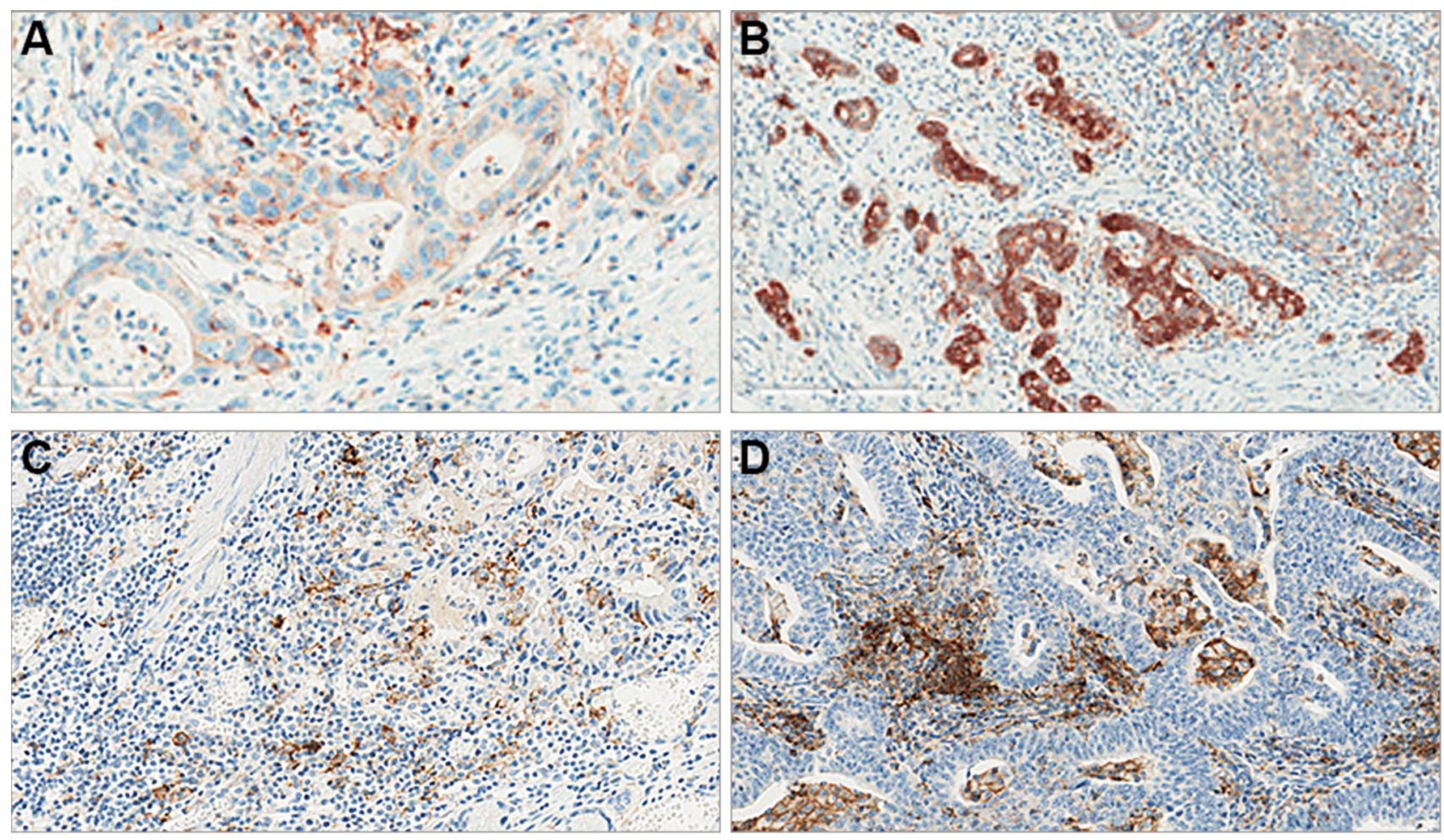

Figure 1. Representative images of immunohistochemical staining for (A-B) tumor cell (TC) PD-L1 positivity, and (C-D) immune cell (IC) PD-L1 positivity.

was observed in TCs and tumor-infiltrating ICs (Figure 1). The relationships between TCs and ICs with PD-L1positive expression and selective clinicopathologic features were investigated (Table I). TC PD-L1 expression was negatively correlated with advanced GC, higher pathologic stage, lymph node metastasis, and perineural invasion $(p<0.0001, p=0.005, p=0.011$, and $p=0.011$, respectively). IC PD-L1 expression was negatively correlated with perineural invasion $(p=0.014)$. IC PD-L1 expression was not significantly correlated with advanced GC, higher stage, or lymph node metastasis.

The relationship between PD-L1 expression and GC molecular subtype was investigated (Table II). IC PD-L1 expression was significantly higher in $\mathrm{EBV}^{+} \mathrm{GCs}$, MSI GCs, and MSS/TP53 wild-type GCs according to ACRG classification $(p<0.0001$ and $p=0.024)$. TC PD-L1 expression was not significantly correlated with molecular classification.

Relationship between GC PD-L1 expression and patient prognosis. Both disease-free and overall survival analyses were performed in all GC patients $(n=286)$. Kaplan-Meier survival curves and log-rank tests revealed significant positive correlations between TC PD-L1 expression and disease-free and overall survival rates $(p<0.0001$ and $p=0.009$, respectively), and between IC PD-L1 expression and disease-free and overall survival rates $(p=0.009$ and $p=0.039$, respectively) (Figure 2).

The prognostic relevance of TC and IC PD-L1 expression was assessed among molecular GC subtypes (Figure 3). In the $\mathrm{EBV}^{-} \mathrm{GC}$ subgroup, TC PD-L1 expression was positively correlated with disease-free and overall survival rates ( $p=0.001$ and $p=0.012$, respectively), and IC PD-L1 expression was positively correlated with disease-free survival $(p=0.010)$. In the MSI GC subgroup, TC PD-L1 expression was positively correlated with disease-free survival $(p=0.036)$, and IC PD-L1 expression was positively correlated with overall survival $(p=0.011)$. In the MSS GC subgroup, TC PD-L1 expression was positively correlated with disease-free and overall survival $(p=0.003$ and $p=0.017$ ), and IC PD-L1 expression was positively correlated with disease-free survival $(p=0.031)$. In the ACRG subgroup, TC and IC PD-L1 expression was positively correlated with overall survival time, but this relationship did not reach statistical significance (Figure 4).

Multivariate analyses using the Cox proportional hazard model for disease-free survival were performed in all GC patients $(n=286)$ to determine the correlation between TC and IC PD-L1 expression and advanced stage GC (EGC vs. AGC), lymph node metastasis, distant metastasis, and younger age at onset (under $61 v s$. over 61 ). TC PD-L1 
Table I. PD-L1 expression relative to clinicopathologic characteristics.

\begin{tabular}{|c|c|c|c|c|c|c|c|}
\hline \multirow[t]{2}{*}{ Characteristics } & \multirow{2}{*}{$\begin{array}{l}\text { Patients } \\
\text { No. }(\%)\end{array}$} & \multicolumn{3}{|c|}{ Tumor cell PD-L1 } & \multicolumn{3}{|c|}{ Immune cell PD-L1 } \\
\hline & & Negative & Positive & $p$-Value & Negative & Positive & $p$-Value \\
\hline Gender & & & & 0.295 & & & 0.755 \\
\hline Male & $189(66.1)$ & $123(68.3)$ & $66(62.3)$ & & $145(65.6)$ & $44(67.7)$ & \\
\hline Female & $97(33.9)$ & $57(31.7)$ & $40(37.7)$ & & $76(34.4)$ & $21(32.3)$ & \\
\hline Age & & & & 0.791 & & & 0.996 \\
\hline$\leq 61$ & $132(46.2)$ & $82(45.6)$ & $50(47.2)$ & & $105(47.5)$ & $27(41.5)$ & \\
\hline$>61$ & $154(53.8)$ & $98(54.4)$ & $56(52.8)$ & & $116(52.5)$ & $38(58.5)$ & \\
\hline EGV vs. AGC & & & & 0.000 & & & 0.260 \\
\hline EGC & $172(60.1)$ & $93(51.7)$ & $79(73.6)$ & & $129(58.4)$ & $43(66.2)$ & \\
\hline AGC & $114(39.9)$ & $87(48.3)$ & $27(26.4)$ & & $92(41.7)$ & $22(33.8)$ & \\
\hline Pathologic stage & & & & 0.005 & & & 0.107 \\
\hline I & $192(67.1)$ & $139(62.9)$ & $53(81.5)$ & & $143(64.7)$ & 49 (75.4) & \\
\hline II-IV & $94(322.9)$ & $82(37.1)$ & $12(18.5)$ & & $78(35.3)$ & $16(24.6)$ & \\
\hline LN metastasis & & & & 0.011 & & & 0.067 \\
\hline Absent & $198(69.2)$ & $115(63.9)$ & $83(78.3)$ & & $147(66.5)$ & $51(78.5)$ & \\
\hline Present & $88(30.8)$ & $65(36.1)$ & $23(21.7)$ & & $74(33.5)$ & $25(21.5)$ & \\
\hline Perineural invasion & & & & 0.011 & & & 0.014 \\
\hline Absent & $213(74.5)$ & $125(69.4)$ & $88(83)$ & & $157(71.0)$ & $56(86.2)$ & \\
\hline Present & $73(25.5)$ & $55(30.6)$ & 18 (17) & & $64(29.0)$ & $9(13.8)$ & \\
\hline
\end{tabular}

EGC: Early gastric cancer; AGC: advanced gastric cancer.

Table II. PD-L1 expression relative to gastric classification.

\begin{tabular}{|c|c|c|c|c|c|c|c|}
\hline \multirow[t]{2}{*}{ Characteristics } & \multirow{2}{*}{$\begin{array}{l}\text { Patients } \\
\text { No. (\%) }\end{array}$} & \multicolumn{3}{|c|}{ Tumor cell PD-L1 } & \multicolumn{3}{|c|}{ Immune cell PD-L1 } \\
\hline & & Negative & Positive & $p$-Value & Negative & Positive & $p$-Value \\
\hline EBV expression & & & & 0.055 & & & 0.000 \\
\hline Negative & $269(94.1)$ & $173(96.1)$ & $96(90.6)$ & & $215(97.3)$ & $54(83.1)$ & \\
\hline Positive & $17(5.9)$ & $7(3.9)$ & $10(9.4)$ & & $6(2.7)$ & $11(16.9)$ & \\
\hline MSI status & & & & 0.596 & & & 0.240 \\
\hline MSI & $60(21.0)$ & $36(20.0)$ & $24(22.6)$ & & $43(19.5)$ & $17(26.2)$ & \\
\hline MSS & $226(79.0)$ & $144(80.0)$ & $82(77.4)$ & & $178(80.5)$ & $48(73.8)$ & \\
\hline TP53 expression & & & & 0.092 & & & 0.065 \\
\hline Wild-type & $179(62.6)$ & $120(66.7)$ & $69(65.1)$ & & $132(59.7)$ & $47(72.3)$ & \\
\hline Mutant & $107(37.4)$ & $60(33.3)$ & 37 (34.9) & & $89(40.3)$ & $18(27.7)$ & \\
\hline ACRG & & & & 0.774 & & & 0.024 \\
\hline MSI & $60(21.0)$ & $36(20.0)$ & $24(21.0)$ & & $19(16.1)$ & $41(24.4)$ & \\
\hline MSS/TP53 mutant & $65(22.7)$ & $44(24.4)$ & $21(19.8)$ & & $30(25.4)$ & $35(20.8)$ & \\
\hline MSS/TP53 wild & $86(30.1)$ & $52(28.9)$ & $34(32.1)$ & & $29(24.6)$ & $57(33.9)$ & \\
\hline MSS/EMT & $75(26.2)$ & $48(26.7)$ & $27(25.5)$ & & $40(33.9)$ & $35(26.2)$ & \\
\hline Lauren & & & & 0.975 & & & 0.167 \\
\hline Intestinal & $176(63.5)$ & $109(63.4)$ & $67(63.8)$ & & $65(55.1)$ & $111(66.1)$ & \\
\hline Diffuse & $73(26.7)$ & $46(26.7)$ & $27(25.7)$ & & $40(33.9)$ & $42(25.0)$ & \\
\hline Mixed & $28(10.1)$ & $17(9.9)$ & $11(10.5)$ & & $13(11.0)$ & $15(8.9)$ & \\
\hline
\end{tabular}

MSI: Microsatellite instability; MSS: microsatellite stability; ACRG: Asian Cancer Research Group classification; EMT: epithelial-mesenchymal transition.

expression was a significant prognostic factor and was positively correlated with overall survival $(p=0.005)$ (Table III), and IC PD-L1 expression was positively correlated with disease-free survival $(p=0.039)$ (Table IV).

\section{Discussion}

PD-L1 is known to play a key role in cancer immune evasion (6). Cancer cells express the PD-L1 co-inhibitory receptor in 

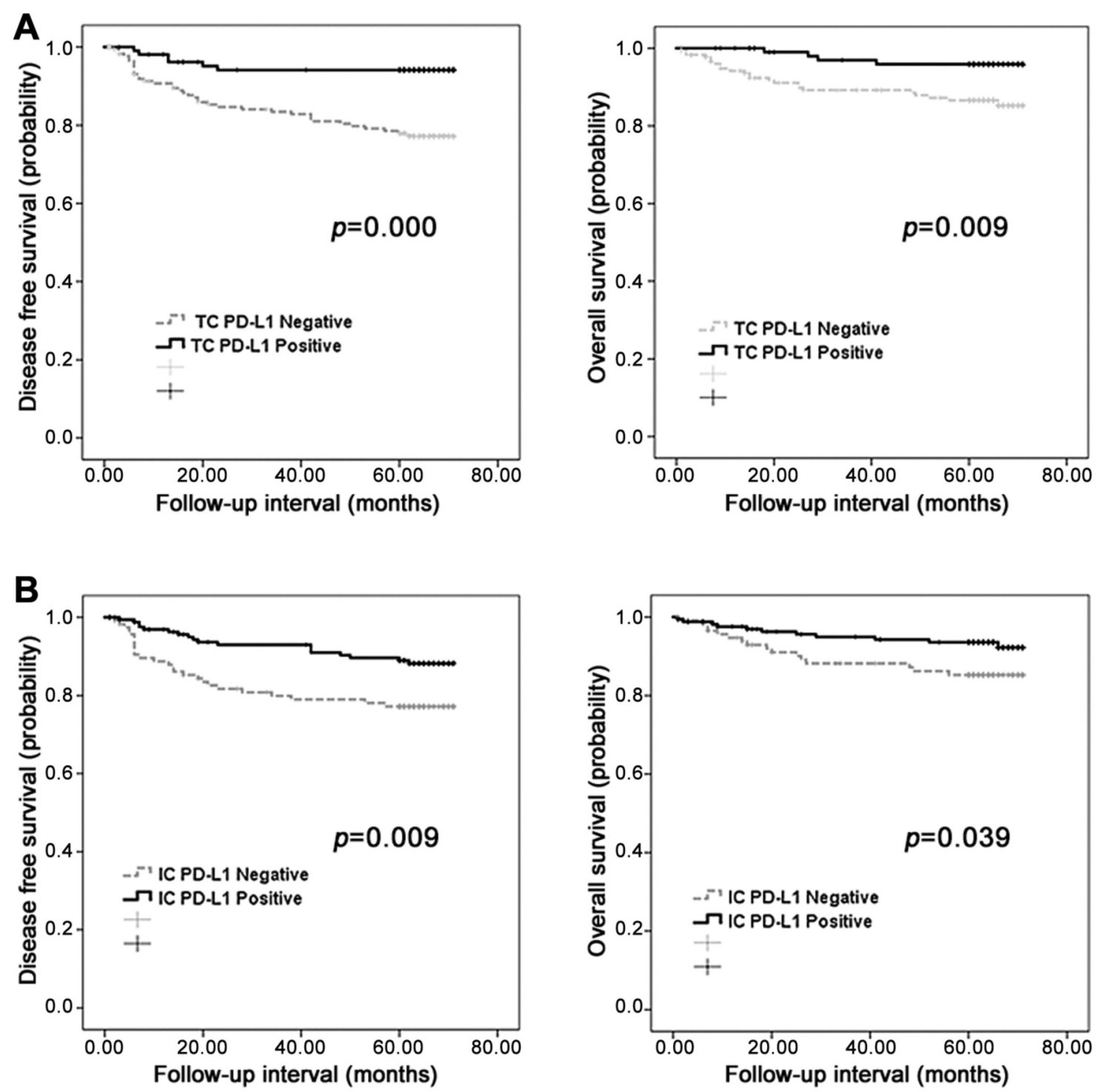

Figure 2. Kaplan-Meier curves of disease-free and overall survival according to (A) tumor cell (TC) and (B) immune cell (IC) PD-L1 expression in all GC patients evaluated ( $n=286)$.

response to immune attack to inhibit T-cell mediated antitumor immunity. Increased PD-L1 expression in solid cancer cells is generally thought to contribute to immune cell activation and is indicative for poor prognosis, however, increased PD-L1 expression also reveals good prognostic impacts. Prior studies have suggested that the role of PD-L1 in disease progression is dependent on cancer type, with a deleterious role in urothelial, renal, and hepatocellular carcinomas (23), despite being associated with improved clinical outcomes in breast cancer and merkel cell carcinoma (24). In addition to TCs, host ICs express PD-L1, which can contribute to tumor cell immunity (25). In prior studies, IC PD-L1 expression was associated with poor prognosis in GC, and improved prognosis in lung and colorectal cancers (26). Thus, the prognostic relevance of TC and IC PD-L1 expression remains elusive and controversial for many cancers.

In the present study, both TC and IC PD-L1 expression was associated with improved prognosis, as demonstrated by uniand multivariate analyses of GC patients. TC PD-L1 expression was negatively correlated with advanced GC, higher pathologic stage, lymph node metastasis, and perineural invasion. Patients with TC and IC PD-L1-positive staining had improved diseasefree and overall survival rates in all cases of GC. Prior studies evaluating the prognostic relevance of PD-L1 expression in GC have yielded opposing results. Prior studies in Chinese and Japanese GC patients suggested that both TC and IC PD-L1 

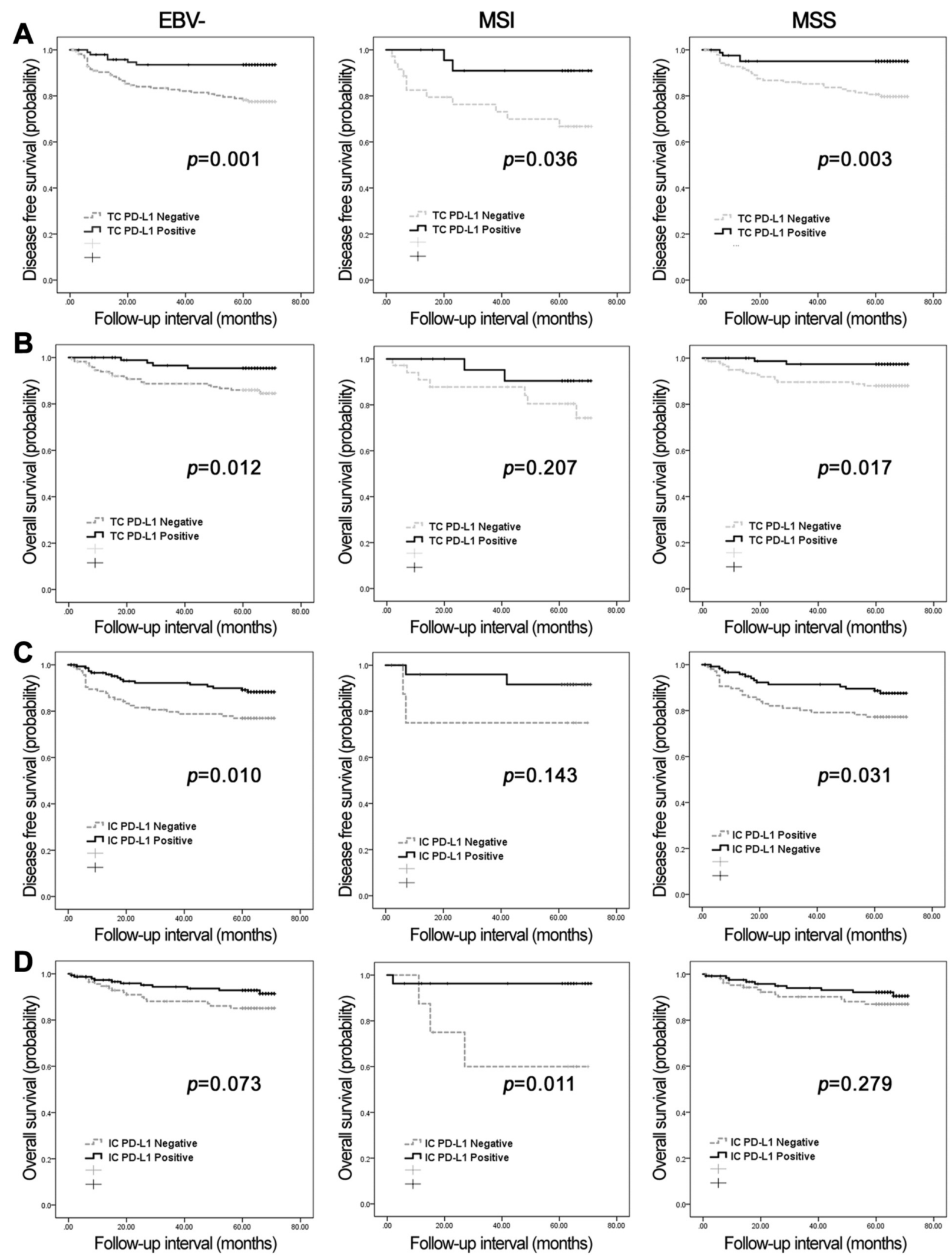

Figure 3. Kaplan-Meier curves of disease-free and overall survival according to (A-B) tumor cell (TC) and (C-D) immune cell (IC) PD-L1 expression in the EBV negative (EBV $\left.V^{-}\right)$, microsatellite instability (MSI), and microsatellite-stable (MSS) subtypes. 

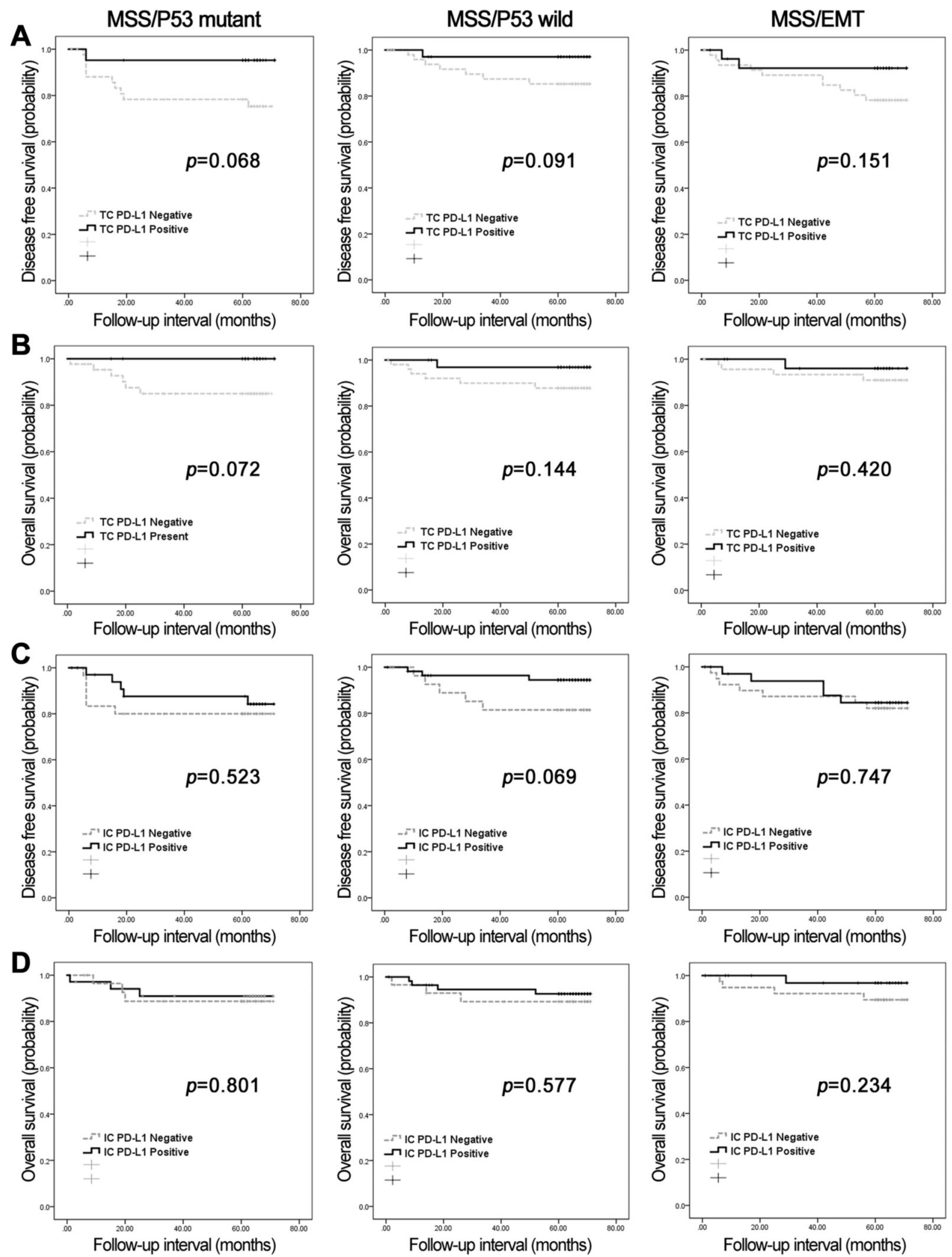

Figure 4. Kaplan-Meier curves of disease-free and overall survival according to (A-B) tumor cell (TC) and (C-D) immune cell (IC) PD-L1 expression in the MSS/TP53 mutant, MSS/TP53 wild-type, and MSS/EMT GC subtypes. 
Table III. Multivariate analysis results for overall survival in gastric adenocarcinoma patients.

\begin{tabular}{lrcr}
\hline & \multicolumn{3}{c}{ Overall survival } \\
\cline { 2 - 4 } & \multicolumn{1}{c}{ HR } & 95\%CI & $p$-Value \\
\hline Tumor cell PD-L1 & 0.229 & $0.082-0.642$ & 0.005 \\
EGC $v s$. AGC & 38.762 & $4.950-303.537$ & 0.000 \\
Lymph node metastasis & 2.275 & $0.921-5.650$ & 0.075 \\
Distant metastasis & 12.324 & $2.336-65.009$ & 0.003 \\
Age (under 61 $v$ s. over 61) & 1.121 & $0.519-2.422$ & 0.771 \\
\hline
\end{tabular}

HR: Hazard ratio; CI: confidence index; Age unit: years; EGC: early gastric cancer; AGC: advanced gastric cancer.

expression were poor prognostic indicators for GC (27-30). Contrastingly, other studies have suggested that TC and IC PDL1 expression are positive prognostic indicators in most Western, some Korean, and some Chinese GC patients (27, 3133). In addition, samples (tissue or serum), resources of antibody (rabbit or mouse), and type of antibody (mono- or polyclonal) were considered in relation with the prognostic significance of PD-L1 expression (30). PD-L1 immunohistochemical assays from different companies (Abcam, Cell Signaling, and DAKO) have been developed and showed different clinical significances $(31,32,34)$. These suggest that the clinical significance of PD-L1 expression varies between patients and could be dependent on many factors including patient ethnicity, samples, and applied types of antibody (14).

We applied a $1 \%$ cut-off level for TC PD-L1 positivity and a $5 \%$ cut-off level for IC PD-L1 positivity to assess the prognostic significance of TC and IC PD-L1 positivity based on the results of the best and most significant separation in survival curves between the applied cut-offs of $1 \%, 5 \%$, $10 \%, 20 \%$, and $50 \%$. Previous studies identified different cut-off values for TC PD-L1 of 1\%, 5\%, 10\%, and 50\% (27), and for IC PD-L1 of $1 \%$ and $5 \%$ (30). Unlike lung cancer, the prognostically significant cut-off values for PD-L1 expression in GC have not yet been validated. Immunotherapeutic drugs for GC are being developed together with diagnostic biomarkers related to PD-L1, so cutoff points to determine PD-L1 positivity will change with patient treatment response (35).

We also assessed PD-L1 expression relative to molecular TCGA and ACRG GC subtypes. IC PD-L1 was significantly upregulated in the $\mathrm{EBV}^{+}$group. A previous study reported the association between PD-L1 expression and CD8 cytotoxic $\mathrm{T}$ cell infiltration in $\mathrm{EBV}^{+} \mathrm{GC}$, which is associated with high proportion of tumor-infiltrating CD8 cytotoxic $\mathrm{T}$ cells (36). Herein, IC and TC PD-L1 expression was associated with improved prognostic outcome in the $\mathrm{EBV}^{-}$, MSI, and MSS subgroups. Previous studies demonstrated
Table IV. Multivariate analysis results for disease-free survival in gastric adenocarcinoma patients.

\begin{tabular}{lrcc}
\hline & \multicolumn{3}{c}{ Disease-free survival } \\
\cline { 2 - 4 } & HR & $95 \% \mathrm{CI}$ & $p$-Value \\
\hline Immune cell PD-L1 & 0.529 & $0.289-0.970$ & 0.039 \\
EGC $v$ s. AGC & 24.270 & $5.631-104.607$ & 0.000 \\
Lymph node metastasis & 3.560 & $1.711-7.405$ & 0.001 \\
Distant metastasis & 0.000 & 0.000 & 0.982 \\
Age (under 61 vs. over 61) & 1.232 & $0.674-2.250$ & 0.498 \\
\hline
\end{tabular}

HR: Hazard ratio; CI: confidence index; Age unit: years; EGC: early gastric cancer; AGC: advanced gastric cancer.

that PD-L1 expression is increased in the $\mathrm{EBV}^{+}$and MSI GC subgroups (30). Further, MSI and TC PT-L1 expression, when combined, were stronger predictive factors for GC patient prognosis (37). Because GCs are molecularly heterogeneous diseases, the TCGA and ACRG guidelines provided a new classification system for GC. Although we evaluated TCGA and ACRG classifications using immunohistochemistry and in situ hybridization, MSI and MSS subgroups can also be separated based on TC and IC expression of PD-L1 $(38,39)$. Integrated assessment of PDL1 expression and molecular classification could better facilitate prediction of GC prognosis.

In conclusion, TC and IC PD-L1 protein levels were confirmed as biomarkers for prediction of improved prognosis in the evaluated cohort of GC patients. Molecular GC classification combined with PD-L1 expression can provide insight into patient prognosis. Additional studies are needed to determine whether PD-L1 expression is predictive of the response to immunotherapy in GC.

\section{Conflicts of Interest}

The Authors declare that there are no known conflicts of interest associated with the work presented in this manuscript. Furthermore, the Authors confirm that the funding provided for these studies did not influence the results in anyway.

\section{Authors' Contributions}

Conceptualization, K.S.Song; Funding acquisition, M.-K.Y.; Investigation, D.H.K., G.E.B and S.-I. L; Methodology, J.S.K. and D.H.K.; Supervision, K.S.Suh and M.-K. Y.; Validation, Writingoriginal draft, D.R and K.S.Song.; Writing-review \& editing, G.E.B. and M.-K.Y.

\section{Acknowledgements}

This study was supported by the research fund of Chungnam National University, grants from the Basic Science Research 
Program through the National Research Foundation of Korea (NRF) funded by the Ministry of Education (2017R1D1A1B04031187), and National Research Foundation of Korea (NRF) funded by the Korea government (MSIT) (2019R1G1A1100578).

\section{References}

1 Global Burden of Disease Cancer Collaboration: Global, regional, and national cancer incidence, mortality, years of life lost, years lived with disability, and disability-adjusted life-years for 32 cancer groups, 1990 to 2015: A systematic analysis for the global burden of disease study. JAMA Oncol 3(4): 524-548, 2017. PMID: 27918777. DOI: 10.1001/jamaoncol.2016.5688

2 Spiegel D, Palta M and Uronis H: Role of chemotherapy and radiation therapy in the management of gastric adenocarcinoma. Surg Clin North Am 97(2): 421-435, 2017. PMID: 28325195. DOI: $10.1016 /$ j.suc.2016.11.013

3 Zhu BY, Yuan SQ, Nie RC, Li SM, Yang LR, Duan JL, Chen YB and Zhang XS: Prognostic factors and recurrence patterns in T4 gastric cancer patients after curative resection. J Cancer 10(5): 1181-1188, 2019. PMID: 30854127. DOI: 10.7150/jca. 28993

4 Xue SA and Stauss HJ: Enhancing immune responses for cancer therapy. Cell Mol Immunol 4(3): 173-184, 2007. PMID: 17601371 .

5 Pham T, Roth S, Kong J, Guerra G, Narasimhan V, Pereira L, Desai J, Heriot A and Ramsay R: An update on immunotherapy for solid tumors: A review. Ann Surg Oncol 25(11): 3404-3412, 2018. PMID: 30039324. DOI: 10.1245/s10434-018-6658-4

6 Pardoll DM: The blockade of immune checkpoints in cancer immunotherapy. Nat Rev Cancer 12(4): 252-264, 2012. PMID: 22437870. DOI: $10.1038 / \mathrm{nrc} 3239$

7 Ahn S, Lee S-J, Kim Y, Kim A, Shin N, Choi KU, Lee C-H, Huh GY, Kim K-M and Setia N: High-throughput protein and mRNA expression-based classification of gastric cancers can identify clinically distinct subtypes, concordant with recent molecular classifications. Am J Surg Pathol 41(1): 106-115, 2017. PMID: 27819872. DOI: 10.1097/PAS.0000000000000756

8 Wu X, Gu Z, Chen Y, Chen B, Chen W, Weng L and Liu X: Application of PD-1 blockade in cancer immunotherapy. Comput Struct Biotec 17: 661-674, 2019. PMID: 31205619. DOI: 10.1016/j.csbj.2019.03.006

9 Muro K, Chung HC, Shankaran V, Geva R, Catenacci D, Gupta S, Eder JP, Golan T, Le DT and Burtness B: Pembrolizumab for patients with PD-L1-positive advanced gastric cancer (KEYNOTE-012): a multicentre, open-label, phase $1 \mathrm{~b}$ trial. Lancet Oncol 17(6): 717-726, 2016. PMID: 27157491. DOI: $10.1016 / \mathrm{S} 1470-2045(16) 00175-3$

10 Le DT, Durham JN, Smith KN, Wang H, Bartlett BR, Aulakh LK, Lu S, Kemberling H, Wilt C and Luber BS: Mismatch repair deficiency predicts response of solid tumors to PD-1 blockade. Science 357(6349): 409-413, 2017. PMID: 28596308. DOI: 10.1126/science.an6733

11 Le DT, Uram JN, Wang H, Bartlett BR, Kemberling H, Eyring AD, Skora AD, Luber BS, Azad NS and Laheru D: Pd-1 blockade in tumors with mismatch-repair deficiency. N Engl J Med 372(26): 2509-2520, 2015. PMID: 26028255. DOI: $10.1056 /$ NEJMoa1500596

12 Cancer Genome Atlas Research Network: Comprehensive molecular characterization of gastric adenocarcinoma. Nature
513: 202-209, 2014. PMID: 25079317. DOI: 10.1038/ nature 13480

13 Wang J, Yu K, Ye X, Do I, Liu S, Gong L, Fu J, Jin J, Choi M and Sohn T: Molecular analysis of gastric cancer identifies subtypes associated with distinct clinical outcomes. Nat Med 21(5): 449-456, 2015. PMID: 25894828. DOI: $10.1038 / \mathrm{nm} .3850$

14 Gu L, Chen M, Guo D, Zhu H, Zhang W, Pan J, Zhong X, Li X, Qian $\mathrm{H}$ and Wang X: PD-L1 and gastric cancer prognosis: A systematic review and meta-analysis. PLoS One 12(8), 2017. PMID: 28796808. DOI: 10.1371/journal.pone.0182692

15 Allred D, Harvey JM, Berardo M and Clark GMJM: Prognostic and predictive factors in breast cancer by immunohistochemical analysis. Mod Pathol 11: 155-168, 1998. PMID: 9504686.

16 Remo A, Fassan M and Lanza G: Immunohistochemical evaluation of mismatch repair proteins in colorectal carcinoma: The AIFEG/GIPAD proposal. Pathologica 108(3): 104-109, 2016. PMID: 28195261.

17 Nitta T, Mitsuhashi T, Hatanaka Y, Miyamoto M, Oba K, Tsuchikawa T, Suzuki Y, Hatanaka KC, Hirano S and Matsuno Y: Prognostic significance of epithelial-mesenchymal transitionrelated markers in extrahepatic cholangiocarcinoma: Comprehensive immunohistochemical study using a tissue microarray. Br J Cancer 111(7): 1363-1372, 2014. PMID: 25077440. DOI: $10.1038 / \mathrm{bjc} .2014 .415$

18 Roh CK, Choi YY, Choi S, Seo WJ, Cho M, Jang E, Son T, Kim H-I, Kim H and Hyung WJ: Single patient classifier assay, microsatellite instability, and Epstein-Barr virus status predict clinical outcomes in stage ii/iii gastric cancer: Results from classic trial. Yonsei Med J 60(2): 132-139, 2019. PMID: 3066683. DOI: $10.3349 / \mathrm{ymj} .2019 .60 .2 .132$

19 Köbel M, Ronnett BM, Singh N, Soslow RA, Gilks CB and McCluggage WG: Interpretation of p53 immunohistochemistry in endometrial carcinomas: Toward increased reproducibility. Int J Gyncol Pathol 38: S123-S131, 2019. PMID: 30666834. DOI: $10.3349 /$ ymj.2019.60.2.132

20 Yemelyanova A, Vang R, Kshirsagar M, Lu D, Marks MA, Shih IM and Kurman RJ: Immunohistochemical staining patterns of p53 can serve as a surrogate marker for tp53 mutations in ovarian carcinoma: An immunohistochemical and nucleotide sequencing analysis. Modern Pathol 24(9): 1248-1253, 2011. PMID: 21552211. DOI: 10.1038/modpathol.2011.85

21 Cristescu R, Lee J, Nebozhyn M, Kim KM, Ting JC, Wong SS, Liu J, Yue YG, Wang J, Yu K, Ye XS, Do IG, Liu S, Gong L, Fu J, Jin JG, Choi MG, Sohn TS, Lee JH, Bae JM, Kim ST, Park SH, Sohn I, Jung SH, Tan P, Chen R, Hardwick J, Kang WK, Ayers M, Hongyue D, Reinhard C, Loboda A, Kim S and Aggarwal A: Molecular analysis of gastric cancer identifies subtypes associated with distinct clinical outcomes. Nat Med 21(5): 449-456, 2015. PMID: 25894828. DOI: 10.1038/nm.3850

22 Bosman FT, Carneiro F, Hruban RH and Theise ND: WHO classification of tumours of the digestive system: World Health Organization; 2010.

23 Wang Q, Liu F and Liu L: Prognostic significance of PD-L1 in solid tumor: An updated meta-analysis. Medicine 96(18): e6369e6369, 2017. PMID: 28471952. DOI: 10.1097/MD. 0000000000006369

24 Wang X, Teng F, Kong L and Yu J: PD-L1 expression in human cancers and its association with clinical outcomes. Onco Targets Ther 9: 5023-5039, 2016. PMID: 27574444. DOI: 10.2147/ OTT.S105862 
25 Tang $\mathrm{F}$ and Zheng P: Tumor cells versus host immune cells: Whose PD-L1 contributes to PD-1/PD-L1 blockade mediated cancer immunotherapy? Cell Biosci 8(1): 34, 2018. PMID: 29744030. DOI: 10.1186/s13578-018-0232-4

26 Kim Y, Wen X, Cho NY and Kang GH: Intratumoral immune cells expressing PD-1/PD-L1 and their prognostic implications in cancer: A meta-analysis. Int J Biol Markers 33(4): 467-474, 2018. PMID: 29779430. DOI: $10.1177 / 1724600818770941$

27 Wen T, Wang Z, Li Y, Li Z, Che X, Fan Y, Wang S, Qu J, Yang X, Hou K, Zhou W, Xu L, Li C, Wang J, Liu J, Chen L, Zhang J, Qu X and Liu Y: A four-factor immunoscore system that predicts clinical outcome for stage II/III gastric cancer. Cancer Immunol Res 5(7): 524-534,2017. PMID: 28619967. DOI: $10.1158 / 2326-6066 . C I R-16-0381$

28 Saito H, Kono Y, Murakami Y, Shishido Y, Kuroda H, Matsunaga T, Fukumoto Y, Osaki T, Ashida K and Fujiwara Y: Highly activated PD-1/PD-L1 pathway in gastric cancer with PD-L1 expression. Anticancer Res 38(1): 107-112, 2018. PMID: 29277762. DOI: 10.21873/anticanres.12197

29 Liu YX, Wang XS, Wang YF, Hu XC, Yan JQ, Zhang YL, Wang W, Yang RJ, Feng YY, Gao SG and Feng XS: Prognostic significance of PD-L1 expression in patients with gastric cancer in East Asia: A meta-analysis. Onco Targets Ther 9: 2649-2654, 2016. PMID: 2722672. DOI: 10.2147/OTT.S102616

30 Gu L, Chen M, Guo D, Zhu H, Zhang W, Pan J, Zhong X, Li X, Qian $\mathrm{H}$ and Wang X: PD-L1 and gastric cancer prognosis: A systematic review and meta-analysis. PloS One 12(8): e0182692-e0182692, 2017. PMID: 28796808. DOI: 10.1371/ journal.pone. 0182692

31 Svensson MC, Borg D, Zhang C, Hedner C, Nodin B, Uhlén M, Mardinoglu A, Leandersson K and Jirström K: Expression of PD-L1 and PD-1 in chemoradiotherapy-naïve esophageal and gastric adenocarcinoma: relationship with mismatch repair status and survival. Frontiers Oncol 9: 136, 2019. PMID: 30931254. DOI: $10.3389 /$ fonc .2019 .00136

32 Böger C, Behrens HM, Mathiak M, Krüger S, Kalthoff $\mathrm{H}$ and Röcken C: PD-L1 is an independent prognostic predictor in gastric cancer of Western patients. Oncotarget 7(17): 24269, 2016. PMID: 27009855. DOI: 10.18632/oncotarget.8169

33 Angell H, Lee J, Kim K, Kim K, Kim S, Park S, Kang W, Sharpe A, Ogden J and Davenport A: PD-L1 and immune infiltrates are differentially expressed in distinct subgroups of gastric cancer. Oncoimmunol 8(2): e1544442, 2019. PMID: 30729066. DOI: 10.1080/2162402X.2018.1544442
34 Tamura T, Ohira M, Tanaka H, Muguruma K, Toyokawa T, Kubo N, Sakurai K, Amano R, Kimura K and Shibutani M: Programmed death-1 ligand-1 (PDL1) expression is associated with the prognosis of patients with stage II/III gastric cancer. Anticancer Res 35(10): 5369-5376, 2015. PMID: 26408698.

35 Hernandez-Martinez JM, Zatarain-Barrón ZL, Cardona AF and Arrieta O: The importance of PD-L1 diagnostic assay harmonization for the selection of lung cancer immunotherapy. J Thorac Dis 10(33): S4096-S4100, 2018. PMID: 30631565. DOI: $10.21037 /$ jtd.2018.10.24

36 De Rosa S, Sahnane N, Tibiletti MG, Magnoli F, Vanoli A, Sessa $\mathrm{F}$ and Chiaravalli $\mathrm{AM}: \mathrm{EBV}^{+}$and MSI gastric cancers harbor high PD-L1/PD-1 expression and high $\mathrm{CD}^{+}$intratumoral lymphocytes. Cancers 10(4): 102, 2018. PMID: 29614789. DOI: $10.3390 /$ cancers 10040102

37 Morihiro T, Kuroda S, Kanaya N, Kakiuchi Y, Kubota T, Aoyama K, Tanaka T, Kikuchi S, Nagasaka T, Nishizaki M, Kagawa S, Tazawa $\mathrm{H}$ and Fujiwara T: PD-L1 expression combined with microsatellite instability/CD8+ tumor infiltrating lymphocytes as a useful prognostic biomarker in gastric cancer. Scient Rep 9(1): 4633, 2019. PMID: 3087460. DOI: 10.1038/ s41598-019-41177-2

38 Ahn S, Lee SJ, Kim Y, Kim A, Shin N, Choi KU, Lee CH, Huh GY, Kim KM and Setia N: High-throughput protein and mRNA expression-based classification of gastric cancers can identify clinically distinct subtypes, concordant with recent molecular classifications. Am J Surg Pathol 41(1): 106-115, 2017. PMID: 27819872. DOI: 10.1097/PAS.0000000000000756

39 Setia N, Agoston AT, Han HS, Mullen JT, Duda DG, Clark JW, Deshpande V, Mino-Kenudson M, Srivastava A and Lennerz JK: A protein and mRNA expression-based classification of gastric cancer. Modern Pathol 29(7): 772-784, 2016. PMID: 27032689. DOI: $10.1038 /$ modpathol.2016.55 